\title{
SPINE METASTASIS OF INTRACRANIAL HEMANGIOPERICYTOMA: CASE REPORT OF TWO TREATMENTS
}

\section{METÁSTASE NA COLUNA DE HEMANGIOPERICITOMA INTRACRANIANO: RELATO DE 2 TRATAMENTOS}

\author{
Fernando Flores de Araujo ${ }^{1}$, Douglas Kenj NarazakI ${ }^{2}$, William Gemio Jacobsen Teixeira ${ }^{2}$, Raphael Martus Marcon ${ }^{3}$, \\ alexandre Fogaça Cristante ${ }^{3}$, Tarcisio Eloy Pessoa Barros Filho ${ }^{3}$
}

1. Universidade de São Paulo, Faculdade de Medicina, Hospital das Clínicas (IOT-HCFMUSP), Instituto de Ortopedia e Traumatologia, São Paulo, SP, Brazil. 2. Universidade de São Paulo, Faculdade de Medicina, Hospital das Clínicas da da (IOT-HCFMUSP), Instituto de Ortopedia e Traumatologia, Grupo de Cirurgia de Coluna, Tumores na coluna, São Paulo, SP, Brazil.

3. Universidade de São Paulo, Faculdade de Medicina, Hospital das Clínicas da da (IOT-HCFMUSP), Instituto de Ortopedia e Traumatologia, Grupo de Cirurgia de Coluna, Laboratório de Investigações Médicas, São Paulo, SP, Brazil.

\section{ABSTRACT}

Objective: To report the use of two techniques (radiosurgery and en bloc vertebrectomy) on the same patient for the treatment of two metastases in different sites of the spine arising from intracranial hemangiopericytoma. Intracranial hemangiopericytomas are rare, comprising approximately $2.4 \%$ of meningeal tumors and $<1 \%$ of all tumors of the central nervous system. Metastases to the spine are even rarer: The largest case series reported in the literature has 5 and 7 cases. Methods: A 37-year-old man diagnosed with intracranial hemangiopericytoma was referred for a metastatic lesion in T12 and underwent en bloc resection using the Tomita technique. Results: The disease evolved with a metastasis to T2 treated by radiosurgery with 1600 cGy. The patient died 1,706 days after the en bloc resection of $\mathrm{T} 12$ and 1324 days after the radiosurgery of $\mathrm{T} 2$, and no recurrence occurred in these locations due to progression of the systemic diseases (liver and central nervous system). Conclusion: This is the first case reported in the literature in which two different techniques were used to treat metastatic lesions in the spine from an intracranial hemangiopericytoma and is unique for its use of two treatments in the same patient. Level of evidence: $V$, case report

Keywords: Spine. Hemangiopericytoma. Radiotherapy. Neoplasm metastasis. Radiosurgery.

\section{RESUMO}

Objetivo: Reportar o uso de duas técnicas (radiocirurgia e vertebrectomia em bloco) no mesmo paciente, para o tratamento de metástases de um hemangiopericitoma intracraniano em dois locais da coluna. Hemangiopericitomas intracranianos são raros, consistindo em cerca de $2,4 \%$ dos tumores da meninge e menos de $1 \%$ de todos os tumores do sistema nervoso central, e metástases para a coluna são ainda mais raras: as maiores séries de casos publicada tinham 5 e 7 casos. Métodos: Um homem de 37 anos com diagnóstico de hemangiopericitoma intracraniano foi encaminhado para resecção em bloco de lesão metastática em T12 com a técnica de Tomita. Resultados: A doença evoluiu com metástase em T2, tratada com radiocirurgia (dose de 1600 cGy). O paciente morreu 1.706 dias após a resecção em bloco de T12 e 1.324 dias após a radiocirurgia de T2, livre de recorrência nessas localizações, devido a progressão sistêmica da doença (para fígado e sistema nervoso central). Conclusão: Este é o primeiro caso na literatura no qual duas técnicas diferentes foram usadas pra tratar lesões metastáticas da coluna de hemangiopericitoma intracraniano, único pelo uso de duas técnicas de tratamento no mesmo paciente. Nível de evidência $V$, relato de caso.

Descritores: Coluna Vertebral. Hemangiopericitoma. Radioterapia. Metástase Neoplásica. Radiocirurgia.

Citation: Araujo FF, Narazaki DK, Teixeira WGJ, Marcon RM, Cristante AF, Barros Filho TEP. Spine metastasis of intracranial hemangiopericytoma: case report of two treatments. Acta Ortop Bras. [online]. 2019;27(2):108-12. Available from URL: http://www.scielo.br/aob.

\section{INTRODUCTION}

Hemangiopericytomas in the bone are rare and are generally the result of the spread of tumors originating in the soft tissues. ${ }^{1-5}$ In the spine, they have been described both in the epidural space and the bone, accounting for around $0.6 \%$ of primary bone tumors of the spine and sacrum. ${ }^{6-8}$
Intracranial hemangiopericytomas account for around $2.4 \%$ of meningeal tumors and less than $1 \%$ of all tumors of the central nervous system (CNS). Although common in most malignant neoplasias, metastases to the spine are extremely rare in intracranial hemangiopericytomas. ${ }^{8-12}$

All authors declare no potential conflict of interest related to this article.

Work conducted at the Department of Orthopaedics and Traumatology, Instituto de Ortopedia e Traumatologia do Hospital das Clínicas da Faculdade de Medicina da Universidade de São Paulo (HC-FMUSP).

Correspondence: Alexandre Fogaça Cristante. Rua Dr. Ovídio Pires de Matos, 333, São Paulo, SP, Brasil. 04018-001. aacristante@gmail.com 
Metastases to the spine may evolve to spinal cord compression syndrome if not treated..$^{12-15}$ Tomita et $a .^{16}$ described a globally recognized technique of posterior-approach en bloc resection for the treatment of primary tumors and metastases of the spine, reporting their experience with 20 cases, with pain relief and improvement of neurological deficit in most. Other authors, however, did not achieve the same outcomes when reproducing the technique. ${ }^{23}$

There is currently no evaluation and management algorithm available for spine metastases and/or spinal cord compression, ${ }^{17,18}$ nor level 1 evidence for intracranial hemangiopericytomas. ${ }^{15-20}$ We present our experience with one case of intracranial hemangiopericytoma with asynchronous metastases in non-contiguous vertebrae, treated with two techniques (radiosurgery and en bloc vertebrectomy) because of the clinical circumstances of the patient.

\section{MATERIALS AND METHODS}

\section{Clinical presentation and examination}

The study was approved by the institutional research ethics committee: Comitê de Ética e Pesquisa do Instituto do Câncer do Estado de São Paulo - CEP/ICESP - number 876/2016. All the participants signed the Free and Informed Consent Form.

A 37-year-old male patient with an intracranial hemangiopericytoma diagnosed 8 years ago was referred to our spine surgery clinic (a public, university referral center for cancer) presenting a lytic lesion in vertebra T12 compatible with metastatic disease during staging (Figures 1 and 2), and complaints of back pain without any neurological deficit. The patient had previously undergone two surgeries for a primary resection and for recurrence in the central nervous system (Figures 3 and 4), and two liver surgeries for the resection of metastatic liver lesions.

\section{Interventions}

\section{En bloc vertebrectomy of T12}

The patient underwent en bloc resection of T12 in two stages. In the first surgery, an en bloc laminectomy was performed (Figure 5). The patient was positioned lying on the stomach, with appropriately placed cushions. An incision was made in the midline; the paraspinal muscle was dissected from the spinous processes and retracted laterally. Pedicle screws were placed two levels above and two

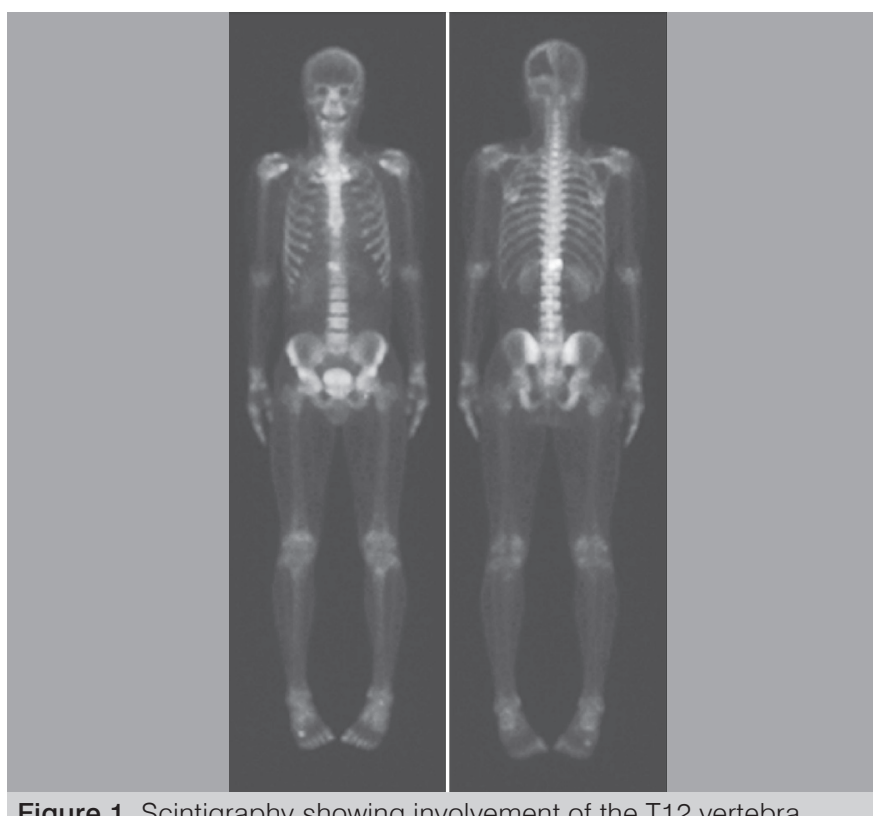

Figure 1. Scintigraphy showing involvement of the T12 vertebra. levels below the lesion ( $T 10, T 11, L 1$, and L2) with fixation of the system using two titanium rods. Resection of the costotransverse joint was performed on both sides, followed by blunt dissection of the pleura, detaching it from the vertebra. Next, resection of the T11 spinous process and its inferior articular processes was performed, making room for the passage of a Gigli saw around

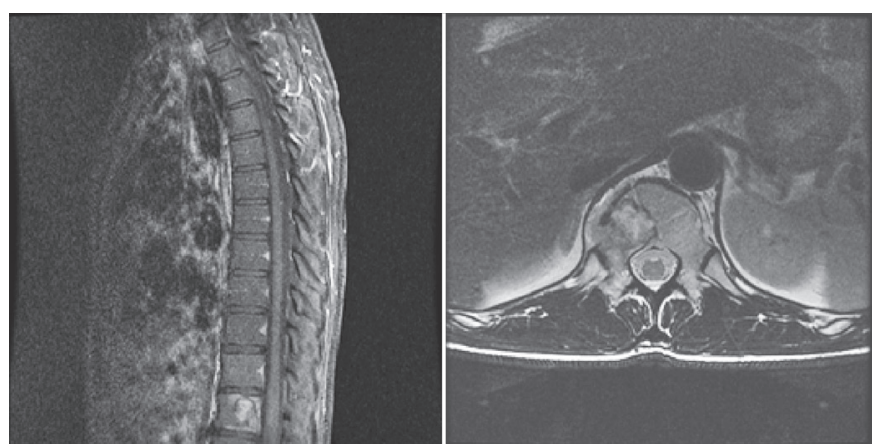

Figure 2. Magnetic resonance imaging (MRI) of the spine in sagittal and axial cuts showing involvement of the T12 vertebra.

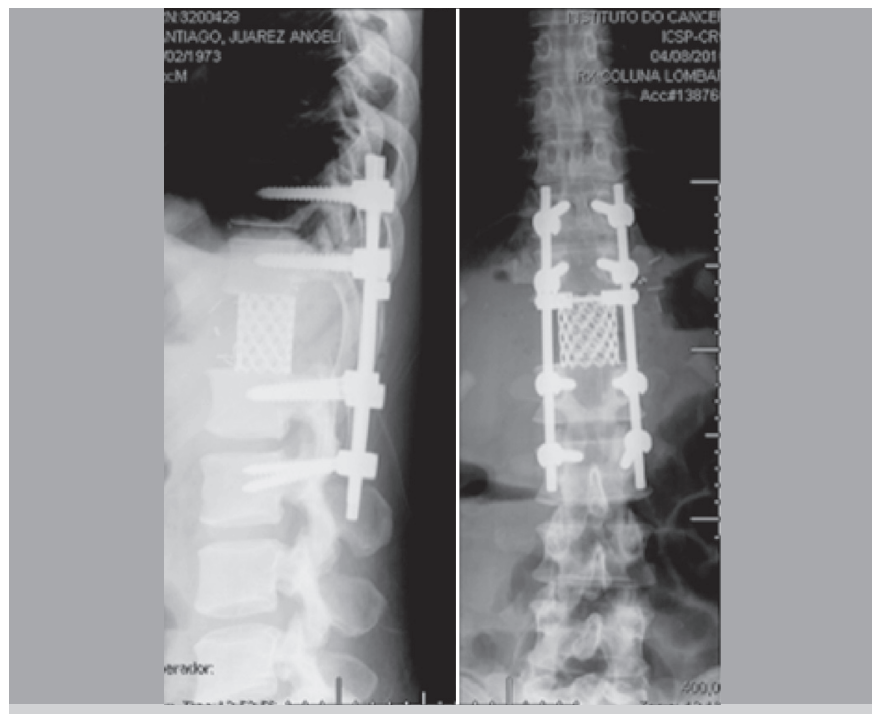

Figure 3. Immediate postoperative $\mathrm{X}$-ray showing the en bloc resection and reconstruction.

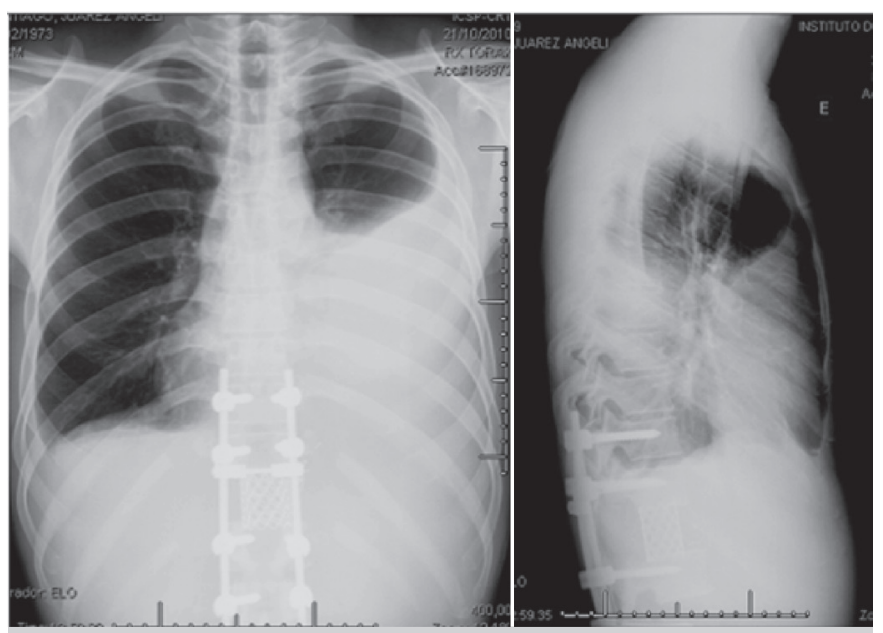

Figure 4. Chest radiograph showing left lung opacity resulting from the chylothorax profile. 

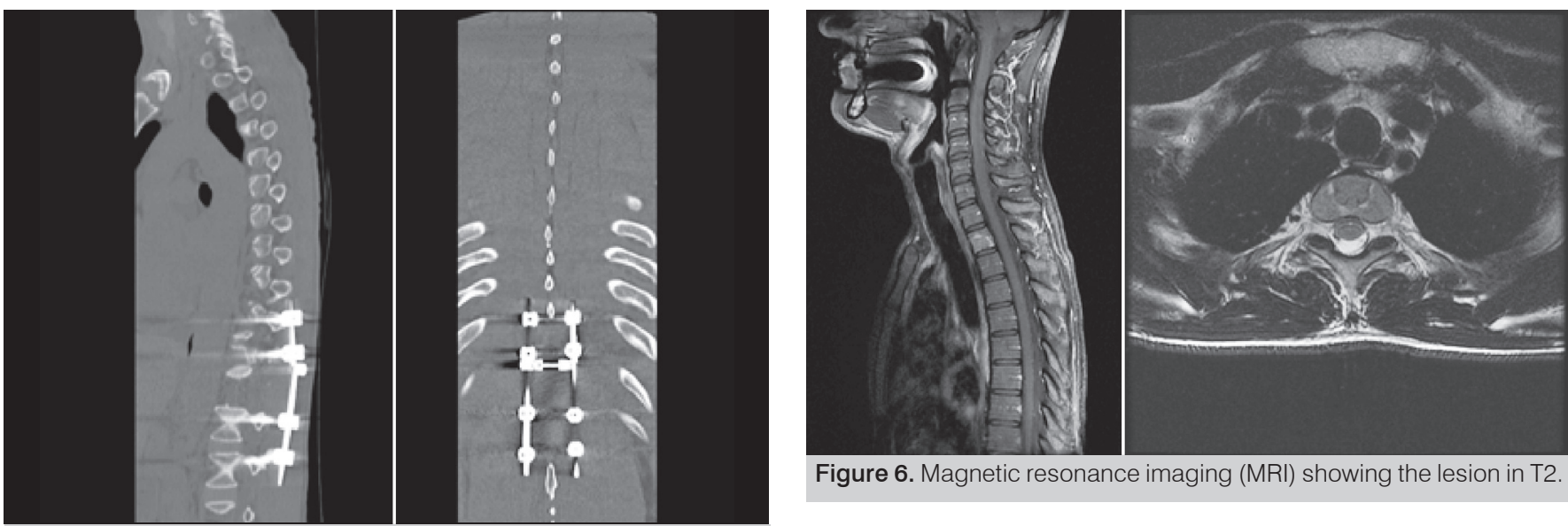

Figure 6. Magnetic resonance imaging (MRI) showing the lesion in T2.

Figure 5. Rod breakage from pseudoarthrosis 14 months after reconstruction.

the pedicles through the intervertebral foramen. After transection of both the pedicles, the posterior elements of T12 were removed in a single block. Temporary fixation was accomplished with two titanium rods. The patient presented no major complications during the postoperative period, only mild pain at the site of the surgical approach, treated with analgesics.

In the second surgery, transection of the ribs was performed at the level of the lesion (T12) and the level immediately above (T11) about $4 \mathrm{~cm}$ from the costotransverse joint, with ligation of the nerve roots and the segmental arteries of the same levels. We performed blunt dissection around the vertebral body, detaching it from the pleura, creating a plane between the anterior structures (pleura, aorta) and the vertebral body. We passed the Gigli saw through the space created, performing an osteotomy through the inferior terminal plate of the cephalic vertebra and the superior vertebral plate of the caudal vertebra. Once free, the vertebral body was rotated and removed en bloc. We placed an anterior reconstruction cage with a graft from the costectomy. We ended with the final fixation of the system. We also performed ligation of the thoracic duct using metal clips. An accidental injury to the pleura occurred during its detachment from the vertebral body and was repaired. During the entire procedure, we maintained the fixation of the system on at least one side, to reduce the neurological risk.

About two months postoperatively, the patient presented significant respiratory discomfort and was hospitalized for pleural effusion (empyema) and diagnosed with chylothorax (Figures 6). He underwent chest drainage for treatment and was put on a lipid restricted diet for two weeks, without any other complications (Figure 7 and 8). One year and six months following surgery, he underwent revision for symptomatic pseudoarthrosis of the T11-L1 arthrodesis, and made good postoperative progress (Figure 9).

\section{Radiosurgery of T2}

In the meantime, the patient presented a new metastatic lesion in T2 (Figure 10), about a year after the first surgery. As the disease was progressing, with new lesions of the liver and the CNS, it was decided to perform radiosurgery on the new lesion with a single dose at 1600 cGy, with no complications.

\section{RESULTS}

The patient remained free from recurrence at the sites where the two treatment modalities were performed, until his death, at 1,706 days after the en bloc resection of the lesion in T12, due to the progression of liver disease and clinical complications.

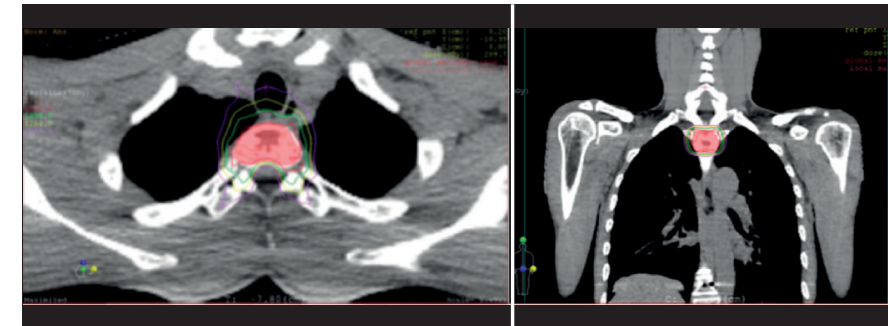

Figure 7. Radiation treatment plan showing isodose curves sparing the spinal cord. Prescription isodose of 16Gy depicted in red.

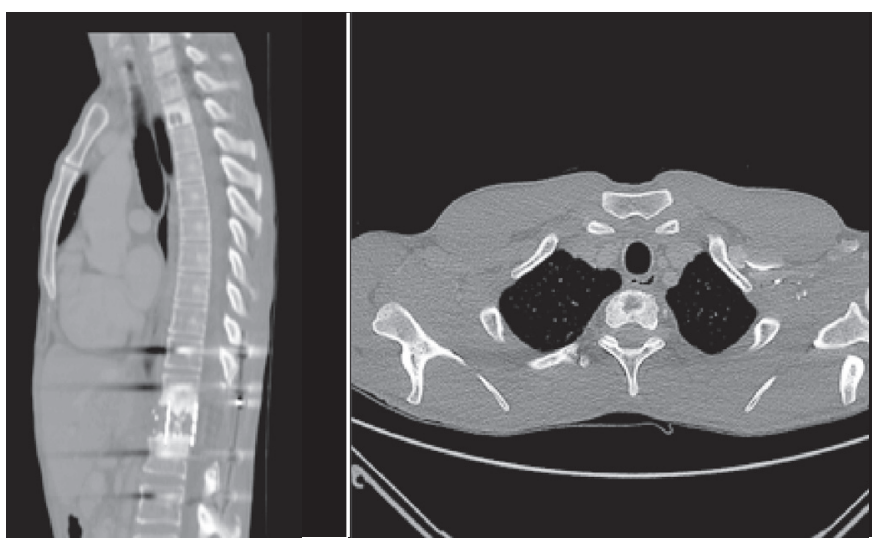

Figure 8. One month after radiosurgery of T2; 12 months following vertebrectomy and reconstruction.

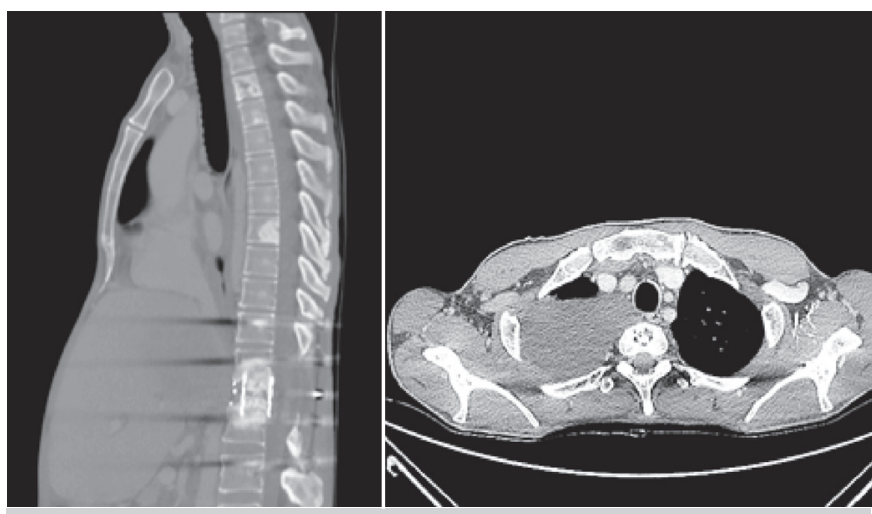

Figure 9. Final follow-up computed tomography (CT) of the T12 lesion 45 months following original surgery; 24 months after revision (consolidation of pseudoarthrosis); and 30 months following radiosurgery. 


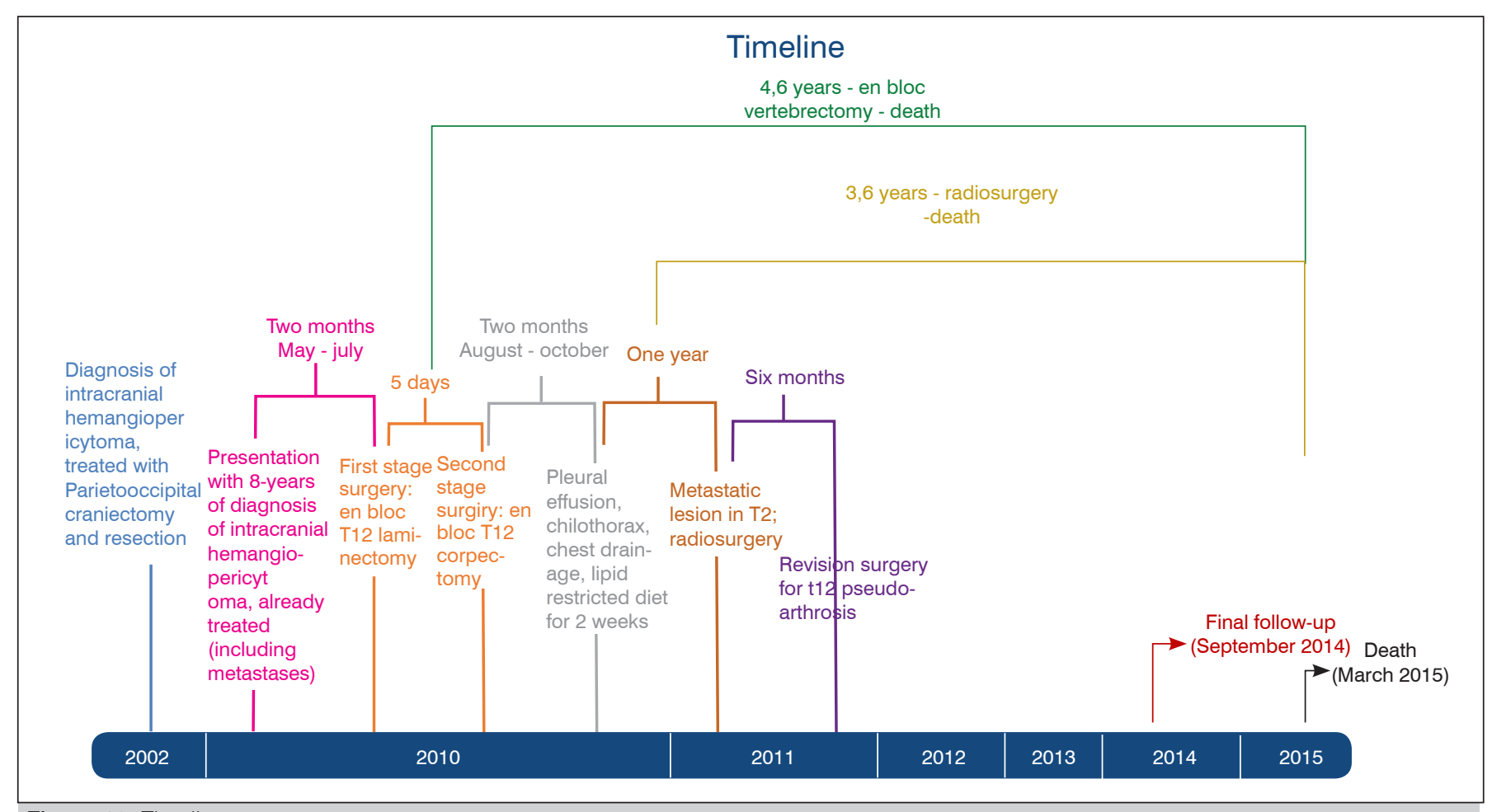

Figure 10. Timeline.

\section{DISCUSSION}

The management of hemangiopericytomas remains controversial, with no level 1 recommendation. ${ }^{1-5}$ Surgical treatment is the central pillar in the treatment of these tumors. ${ }^{2}$ There are no guidelines that indicate the ideal resection margins of metastases, which is even more problematic in the spine, where the margins are often bordered by vital structures. ${ }^{2-6}$ In the experience reported, we achieved disease-free margins using the posterior approach en bloc resection technique described by Tomita et al., ${ }^{16}$ without any significant neurological damage, and without any motor or sphincter function loss. It is a highly demanding technique with potential risks, and its use is only recommended for patients with metastases without paraspinal extension. ${ }^{17}$

Chemotherapy plays a purely palliative role in the treatment of hemangiopericytoma, with poor results reported in the literature. ${ }^{18}$ Stereotactic radiosurgery (gamma-knife, cyber-knife), has promising results ${ }^{18}$ and radiosurgery can also increase survival and the time free from local recurrence, ${ }^{19}$ but does not reduce the risk of distant metastases, which cause significant morbidity and mortality. En bloc resection is a high-risk procedure, with an average duration of 12.1 hours, average bleeding of 3.7 liters, and a complication rate of $36.3 \%$ reported in the literature. ${ }^{20}$ Our patient had two significant postoperative complications: a profile of chylothorax and symptomatic pseudoarthrosis. Although it did not affect patient survival time, it resulted in higher morbidity, with two additional hospitalizations and a third surgery in addition to the two planned ones.

In the lesion of T2, radiosurgery with a single dose of 1600 cGy was chosen, obtaining a good response with 1324 days of follow-up free from local recurrence and without complications from the procedure. Although no complications were observed in our case, up to $20 \%$ of patients can develop a profile of transient pain postoperatively ${ }^{20}$ and $20 \%$ may develop fractures of the vertebrae submitted to SSR, making the proper selection of patients and the proper use of the technique important, since these fractures are observed in patients with lytic spine lesions affecting more than half of the vertebral body. Exaggerated radiation (> 20 cGy) also influences this complication. ${ }^{20}$

\section{CONCLUSION}

This is the first case reported in the literature in which two different techniques were used to treat metastatic lesions of the spine from intracranial hemangiopericytoma, unique because the two forms of treatment were used in the same patient. We observed survival free from recurrence for 1706 days, longer than that reported from the original technique (522 days), ${ }^{16}$ and comparable to the more recent literature (1873 days in patients with disseminated metastases). ${ }^{17}$ In our opinion, both techniques can be effective if executed with precision and discretion, observing the main determinants of success of the treatment, the extent of the disease, and presence of spinal instability, and the neurological and oncological components.

\section{ACKNOWLEDGEMENT}

The authors wish to thank dr. Pedro Henrique Xavier Nabuco de Araújo for treating the patient performing the surgical access, and dr. André Tsin Chin Chen for performing radiosurgery. Both provided detailed data about the patients, that allowed this case description.

AUTHORS' CONTRIBUTIONS: All authors contributed individually and significantly for this study development as follows. FFA (0000-0002-0746-265X)*: manuscript writing, critical revision and data collection (surgeries); DKN (0000-0001-7895-4830) * data collection (from surgeries), statistical analysis, critical revision of the manuscript; WGJT (0000-0001-9036-629X)*: data collection (from surgeries), data analysis and manuscript writing; RMM (0000-0001-5958$5646)^{*}$ : data collection (imaging evaluation) and critical review of the manuscript; AFC (0000-0002-7797-5274)*: study design and planning, provision of administrative resources, manuscript writing and revision; TEPBF (0000-0002-7969-7845)* : study design and planning, data collection (from surgeries), manuscript writing, statistical analysis and review. All authors reviewed the final version to be published and are responsible for its contents. ${ }^{\star}$ ORCID (Open Researcher and Contributor ID) 


\section{REFERENCES}

1. Zambo I, Vesel K. [WHO classification of tumours of soft tissue and bone 2013: the main changes compared to the 3rd edition]. Cesk Patol. 2014;50(2):64-70.

2. Schiariti M, Goetz P, El-Maghraby H, Tailor J, Kitchen N. Hemangiopericytoma: long-term outcome revisited. Clinical article. J Neurosurg. 2011;114(3):747-55.

3. Mena H, Ribas JL, Pezeshkpour GH, Cowan DN, Parisi JE. Hemangiopericytoma of the central nervous system: a review of 94 cases. Hum Pathol. 1991;22(1):84-91.

4. Sundaram C, Uppin SG, Uppin MS, Rekha JS, Panigrahi MK, Purohit AK, et al A clinicopathological and immunohistochemical study of central nervous system hemangiopericytomas. J Clin Neurosci. 2010;17(4):469-72.

5. Radley MG, McDonald JV. Meningeal hemangiopericytoma of the posterior fossa and thoracic spinal epidural space: a case report. Neurosurgery. 1992;30(3):446-52.

6. Wu Z, Yang H, Weng D, Ding Y. Rapid recurrence and bilateral lungs, multiple bone metastasis of malignant solitary fibrous tumor of the right occipital lobe: report of a case and review. Diagn Pathol. 2015;10:91.

7. Melone AG, D'Elia A, Santoro F, Salvati M, Delfini R, Cantore G, et al. Intracrania hemangiopericytoma--our experience in 30 years: a series of 43 cases and review of the literature. World Neurosurg. 2014;81(3-4):556-62.

8. Liu HG, Yang AC, Chen N, Yang J, Qiu XG, Zhang JG. Hemagiopericytomas in the spine: clinical features, classification, treatment, and long-term follow-up in 26 patients. Neurosurgery. 2013;72(1):16-24.

9. Lin YJ, Tu YK, Lin SM, Shun CT. Primaryhemangiopericytoma in the axis bone: case report and review of literature. Neurosurgery. 1996;39(2):397-9.

10. Lee JK, Kim SH, Joo SP, Kim TS, Jung S, Kim JH, et al. Spinal metastasis from cranial meningeal hemangiopericytomas. Acta Neurochir (Wien). 2006;148(7):787-90.

11. Woitzik J, Sommer C, Krauss JK. Delayed manifestation of spinal metastasis: a special feature of hemangiopericytoma.Clin Neurol Neurosurg. 2003;105(3):159-66.

12. Mazel C, Balabaud L, Bennis S, Hansen S. Cervical and thoracic spine tumor management: surgical indications, techniques, and outcomes. Orthop Clin North Am. 2009;40(1):75-92.

13. Kaloostian PE, Yurter A, Zadnik PL, Sciubba DM, Gokaslan ZL. Current paradigms for metastatic spinal disease: an evidence-based review. Ann Surg Oncol. 2014;21(1):248-62.

14. Rades D, Huttenlocher S, Dunst J, Bajrovic A, Karstens JH, Rudat V, et al. Matched pair analysis comparing surgery followed by radiotherapy and radiotherapy alone for metastatic spinal cord compression. J Clin Oncol. 2010;28(22):3597-604.

15. Kelly ML, Kshettry VR, Rosenbaum BP, Seicean A, Weil RJ. Effect of a randomized controlled trial on the surgical treatment of spinal metastasis, 2000 through 2010: a population-based cohort study. Cancer. 2014;120(6):901-8.

16. Tomita K, Kawahara N, Baba H, Tsuchiya H, Nagata S, Toribatake Y. Total en bloc spondylectomy for solitary spinal metastases. Int Orthop. 1994;18(5):291-8.

17. Sakaura H, Hosono N, Mukai Y, Ishii T, Yonenobu K, Yoshikawa H. Outcome of total en bloc spondylectomy for solitary metastasis of the thoracolumbar spine. J Spinal Disord Tech. 2004;17(4):297-300.

18. Tokuhashi Y, Uei H, Oshima M, Ajiro Y. Scoring system for prediction of metastatic spine tumor prognosis. World J Orthop. 2014;5(3):262-71.

19. Tomita K, Kawahara N, Kobayashi T, Yoshida A, Murakami H, Akamaru T. Surgical strategy for spinal metastases. Spine (Phila Pa 1976). 2001;26(3):298-306.

20. Chiang A, Zeng L, Zhang L, Lochray F, Korol R, Loblaw A, et al. Pain flare is a common adverse event in steroid-naïve patients after spine stereotactic body radiation therapy: a prospective clinical trial. Int J Radiat Oncol Biol Phys. 2013;86(4):638-42 